\title{
ENTRE LINGUAGEM, PENSAMENTO E POLÍTICA
}

\section{UMA RESENHA DO IVRO: RANCIÈRE, J. LES MOTS ET LES TORTS. DIALOGUE AVEC JAVIER BASSAS. PARIS: LA FABRIQUE ÉDITIONS, 2021. ISBN: 9782358722087}

\author{
Renan Ferreira da Silva \\ (Universidade de São Paulo) \\ renan2.silva@usp.br
}

Recibido: $16 / 11 / 2021$

Aprobado: 14/01/2022

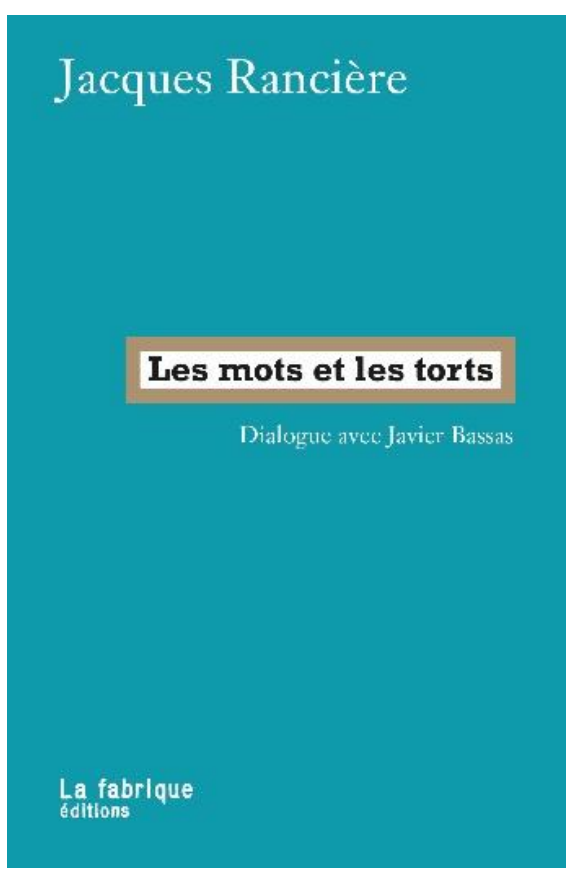

Publicado em fevereiro de 2021 pelas Éditions La Fabrique, Les mots et les torts é o último livro do filósofo franco-argelino Jacques Rancière, professor emérito da Universidade de Paris VIII, e um dos grandes expoentes da filosofia francesa contemporânea. Autor de obras como La Mésentente ( $O$ desentendimento), Le partage du sensible (A partilha do sensivel), Aisthesis: Scénes du régime esthétique de l'art (Aisthesis: Cenas do regime estético da arte), para mencionar somente algumas, Rancière caminha na intersecção entre os campos da estética e da política, a qual deve ser compreendida pela sua ideia de "partilha do sensível", formulada pelo filósofo como um "sistema de evidências que revela, ao mesmo tempo, a existência de um comum e dos recortes que nele definem lugares e partes respectivas", definindo, simultaneamente, "um comum partilhado e suas partes exclusivas" (Rancière, 2009: 15), revelando, em seus trabalhos, a "estética primeira" que se encontra na base de toda política, um sistema de formas a priori que determina o que se pode ou não sentir numa dada comunidade sensível. Tais trabalhos passaram a receber uma atenção mais crítica, rigorosa e sistemática dos meios acadêmicos do Brasil apenas recentemente, se comparados, por exemplo, com a recepção das obras de Michel Foucault e Gilles Deleuze, apenas para citar dois grandes nomes do pensamento francês.

O livro é escrito em formato de diálogo, gênero caro ao filósofo, haja vista a sua insistência em conceder entrevistas nos últimos anos, como se pode notar pelo número considerável de artigos e livros decorrentes da interlocução de Rancière com pesquisadores, professores e teóricos interessados em sua obra. Exemplo disso são os livros La méthode de l'égalité: Entretien avec Laurent Jeanpierre et Dork Zabunyan (2012), En quel temps vivons-nous?: Conversation avec Eric Hazan (2017), La méthode de la scène: Conversation avec Adnen Jdey (2018), e do recente Le travail des images: Conversations avec Andrea Soto Calderón (2019). Les mots et les torts nasce, assim, desse grande movimento dialógico, resultado do seminário organizado pelo filósofo e tradutor espanhol Javier Bassas, professor da Universidade de Barcelona, juntamente com Rancière, ocorrido em La Virreina Centre de la Imatge, em 2018. A partir do diálogo estabelecido com o filósofo espanhol, Rancière concordou em prosseguir com suas reflexões por escrito, respondendo a novos questionamentos, originando a obra que temos em mãos, infelizmente ainda sem tradução para o português.

Desse modo, é significativo frisar a importância da forma de Les mots et les torts. A constância do diálogo na produção teórica de Rancière é algo notável, mas não ocasional, como bem lembram Laurent Jeanpierre et Dork Zabunyan (Rancière, 2012: 7-8). De acordo com o próprio Rancière em conversa com os pesquisadores, uma entrevista não deve ser confundida com os resultados de um trabalho de 
pesquisa. Entretanto, ela denota uma parte não negligenciável do "método de igualdade", processo defendido por Rancière desde o começo de sua produção teórica nos anos 1970. Para o filósofo, uma entrevista não diminui a eficácia ou a potência do pensamento, comumente considerado em sua efetividade extrema no trabalho de pesquisa. Com o método de igualdade, Rancière postula que "não há lugar próprio para o pensamento", pois o mesmo encontra-se em todo o lugar, estando "sempre em atividade" (Rancière, 2012: 7-8).

Se o pensamento não conserva um lugar determinado, então o que dizer da sua relação com as palavras, em especial sob a forma da escrita? Sendo um dos temas caros ao trabalho de Rancière, a ligação entre palavra, escrita e pensamento será explicitada em Les mots et les torts. Para o filósofo, as palavras, ao contrário do que foi legado pela tradição platônica (a qual privilegia o logos, isto é, o discurso em toda sua presença em detrimento da mudez da escrita), não são sombras opostas à sólida realidade das coisas. Elas próprias são realidades cuja ação constrói ou subverte uma ordem do mundo. Constituindo realidades em si mesmas, as palavras se encarnam pela atividade escritural, estabelecendo ou subvertendo uma determinada partilha do sensível. E tal relação disruptiva entre linguagem e pensamento é o próprio fio condutor de Les mots et les torts, como podemos constatar logo no início: a partir da lógica da igualdade, a qual constitui o fundamento do pensamento rancièriano, como pensar uma palavra (parole) que não a traia? (Rancière, 2021: 11).

Toda atividade do pensamento, lembra Bassas, implica uma capacidade intelectual, a qual é, segundo Rancière, algo comumente partilhado, primordial e axiomático, encontrada no princípio de toda política: a igualdade das inteligências. Esta igualdade, atesta o filósofo, é o testemunho de toda contingência da ordem, revelando a falta de fundamento de toda ordenação social. Nesse sentido, se todos possuem a mesma capacidade intelectual, então o trabalho do pensamento não seria exclusividade e privilégio de alguns, como quer a lógica da divisão do trabalho que liga cada corpo a determinada atividade, hierarquizando as práticas e, no limite, instaurando a dominação do pensamento sobre o trabalho manual ao distinguir dois tipos de seres humanos, uns ligados à atividade de abstração, sábios que argumentam e explicam, enquanto outros encontram seu destino atrelado à materialidade do mundo, ignorantes sem a posse do discurso intelectual. Desse modo, o exercício filosófico de Rancière busca romper com essa lógica "que faz de uma potência comum [a inteligência] um trabalho específico" (Rancière, 2016: 247), na tentativa de construir, através da escrita, um "plano de igualdade entre os blocos de linguagem e os blocos de pensamento que são normalmente separados" (Rancière, 2016: 18). pela divisão das funções estabelecida pela ordem social. Aqui revela-se outra ideia principal do livro, qual seja, a de que a escrita não deve ser tomada como pura ilustração do pensamento. Ela é a própria atividade do pensamento, cujo trabalho rompe o fio do tecido consensual que compõem as relações verticalizadas entre pensamento e sensibilidade, embaralhando, dessa maneira, as hierarquias entre os diferentes modos discursivos. Seja na escrita filosófica, seja nas práticas de emancipação políticas, o que Rancière procura é um plano de horizontalidade, uma ação que embaralhe as divisões que separam e definem em seu lugar próprio a experiência da práxis e a atividade do pensamento.

É importante frisar que a temática de Les mots et les torts - as relações entre linguagem, pensamento e política - é parte essencial da produção teórica de Rancière. Na ocasião de outra entrevista, concedida à revista Diacritics, o filósofo é interpelado por Davide Panagia a respeito de seu empreendimento filosófico: seria possível caracterizar suas pesquisas a respeito do pensamento democrático como uma "poética da política", haja vista o destaque concedido em seus escritos à eficácia política das palavras? (Rancière, 2000: 113). Ora, se percorremos a sua bibliografia, poderemos perceber que essa eficácia se encontra presente em diversos momentos de seu pensamento: em Les noms de l'histoire, Essai de poétique du savoir, publicado em 1992, Rancière procurou mostrar, por exemplo, que o excesso de palavras entre os indivíduos está na base de todo acontecimento revolucionário, um excesso que ocorre "na forma específica de um deslocamento do dizer: uma apropriação "fora da verdade da palavra do outro' que a faz significar diferentemente", conflagrando os discursos, embaralhando os seus tempos e deslocando as palavras de seu caminho naturalizado (Rancière, 2014: 46, 52). E é por meio dessa abundância e dessa confusão que embaralha os discursos e desvia as palavras em relação às coisas que, 
de acordo com Rancière, existe história, justamente porque não há harmonia entre as palavras e as coisas, entre nomes e propriedades, entre nominações e classificações (Rancière, 2014: 52-56).

Essa temática também pode ser encontrada em La Mésentente (1995), sua principal obra sobre filosofia política. Nela, Rancière elabora o conceito de subjetivação política, compreendida enquanto o processo através do qual aqueles que não têm sua parte reconhecida na ordem social, aqueles que são invisíveis e inaudíveis politicamente, que não detêm nenhuma parte na comunidade, a "parcela dos sem-parcela" (Rancière, 1996: 24), passam a declarar e a enunciar verbalmente, de maneira coletiva, a sua reivindicação à existência política - reivindicação que pode ser consciente ou não. Essa luta por reconhecimento político deve ser interpretada como a manifestação por parte dos "sem-parcela" na comunidade - o demos ateniense, ou ainda o proletariado moderno - de um erro fundamental, de um litígio depositado na origem da trama social, isto é, de um "dano" (tort) causado pelas outras partes e que se encontra no princípio de organização da comunidade política: uma contagem das parcelas e das partes da comunidade, uma contagem que é, na verdade, uma "falsa contagem, uma dupla contagem ou um erro na contagem" (Rancière, 1996: 22), pois relega o povo à inexistência, ao mesmo tempo que revela a contingência de toda organização social. É somente através do tratamento desse dano, por meio da subjetivação, que os sujeitos políticos podem reconfigurar o plano estético da comunidade, isto é, a sua dimensão sensível. Desse modo, pensando a política como desentendimento, Rancière a compreende não como um meio harmônico, por meio do qual possa haver concordância em torno do bem comum, mas como um conflito capital, como a enunciação de um dano, a expressão, pela palavra, daqueles que não têm parte. Nesse contexto, o "excesso de palavras" surge sob o conceito de "literaridade", o qual indica a potencialidade desse excesso de desfazer "a relação entre a ordem das palavras e a ordem dos corpos" (Rancière, 1996: 49). Além disso, a "literaridade" refere-se, simultaneamente, ao regime da escrita, à condição de possibilidade da literatura e, paradoxalmente, ao seu limite, aquilo que a torna indiscernível de outras formas de discurso. $\mathrm{Na}$ mesma linha, o filósofo franco-argelino principia sua discussão em Aux bords de la politique (1990) com uma viagem ao tema do fim da política, identificado enquanto o fim da promessa - o que ele traz no regresso, senão a identificação entre política e promessa? Uma promessa, sabemos, não é nada menos do que a intenção da palavra, ou a palavra intencionada, o que torna o excesso a essência mesma da promessa.

Esses exemplos servem para ilustrar e destacar essa questão fundamental que se encontra no cerne da filosofia de Rancière: a sua preocupação em torno das palavras, de sua eficácia política e de sua força disruptiva, do poder que seu excesso representa nos campos da política, das artes e dos saberes, bem como de seus efeitos na reconfiguração da ordem do sensível. Tal preocupação não é acidental ou circunstancial, pois é proveniente de um ponto específico e importante de seu pensamento, oriunda dos seus anos de formação intelectual, e que pode ser fixado, como afirma o filósofo Alain Badiou, na relação dialética entre saber e poder, entre saber e autoridade (Badiou, 2015:178). Nesse sentido, Les mots et les torts encontra-se no rastro dessa preocupação, e nesta obra o filósofo sintetiza, através de um discurso que evidencia o método da igualdade, os diferentes momentos de sua reflexão e pesquisa filosóficas que versam sobre o tema da linguagem e da política, confrontando questões que vão desde a sua posição face ao althusserianismo, até outras que envolvem a sua relação com a fenomenologia ou mesmo com a desconstrução derridiana. Não por acaso o título do livro: em alusão explícita ao importante escrito de Michel Foucault, Les mots et les torts apresenta ao leitor aquilo de que suas páginas são constituídas, a saber, de reflexões sobre as palavras e os "danos", isto é, a forma específica da igualdade, o ponto polêmico e universal segundo o qual, de acordo com Rancière, a política torna-se possível.

\section{Referências}

Badiou, A. (2015) A aventura da filosofia francesa no século XX. Autêntica Editora. Belo Horizonte.

Rancière, J. (1996). O desentendimento. $1^{\text {a }}$. ed. Editora 34. São Paulo.

Rancière, J. (2009) A partilha do sensível. Editora 34. São Paulo. 
Rancière, J. (2012). La méthode de l'égalité. Entretien avec Laurent Jeanpierre et Dork Zabunyan. Bayard Éditions. Montrouge.

Rancière, J. (2014). Os nomes da história: ensaio de poética do saber. $1^{a}$. ed. Unesp. São Paulo.

Rancière, J. (2016). "L'arme théorique d'un recommencement du marxisme". In: Lasowski, A. W. Althusser et nous. PUF - Presses Universitaires de France. Paris.

Rancière, J. (2021). Les mots et les torts. Dialogue avec Javier Bassas. Éditions La fabrique. Paris.

Rancière, J.; Panagia, D. (2000). "Dissenting Words: A Conversation with Jacques Rancière". In: Diacritics. 30(2). 